GRASAS Y ACEITES 70 (4)

October-December 2019, e333

ISSN-L: 0017-3495

https://doi.org/10.3989/gya.0928182

\title{
Composition, properties, stability and thermal behavior of tamarind (Tamarindus indica) seed oil
}

\author{
M.G. Chacón-Fernández ${ }^{\mathrm{a}}$, M.R. Hernández-Medel ${ }^{\mathrm{a}}$, M. Bernal-González , \\ M.C. Durán-Domínguez-de-Bazúa ${ }^{\mathrm{b}}$ and J.A. Solís-Fuentes ${ }^{\mathrm{a}, \varpi}$ \\ ${ }^{a}$ Instituto de Ciencias Básicas, Universidad Veracruzana. Av. Dos Vistas s/n carretera \\ Xalapa-Las Trancas, 91000 Xalapa, Ver., México Fax (+52) -2841-8931. \\ ${ }^{\mathrm{b}}$ Facultad de Química, UNAM. Conjunto "E", Labs 301-303, Ciudad Universitaria, 04510 México, \\ D.F. Fax (+52) 55-5622-5303. Correo-e (e-mail): mcduran@.unam.mx \\ Corresponding author: jsolis@uv.mx
}

Submitted: 01 September 2018; Accepted: 24 January 2019; Published online: 29 July 2019

SUMMARY: The composition, thermal stability and phase behavior of tamarind (Tamarindus indica) seed oil were analyzed to contribute to the exploration of their potential uses. The oil was extracted from the kernel of the tamarind seed with hexane, and its main physical, chemical and thermal properties were analyzed by infrared spectrometry, gas chromatography-mass spectrometry, DSC, and TGA. The results showed that the tamarind seed had a $3.76 \pm 0.20 \%$ oil with a saponification index of $174.80 \pm 9.87 \mathrm{mg} \mathrm{KOH} / \mathrm{g}$ and the major fatty acids were lignoceric $(20.15 \%)$, oleic $(18.99 \%)$ and palmitic (11.99\%). Stearic, behenic, linoleic, arachidic, and other fatty acids were also present. TGA and DSC showed that in an inert atmosphere, the triacylglycerols of tamarind seed oil (TSO) are decomposed in a single stage that starts at $224.1^{\circ} \mathrm{C}$ and in an air atmosphere in three stages, initiating its decomposition at $218^{\circ} \mathrm{C}$. The TSO showed crystallization and fusion curves with a single maximum peak with $\mathrm{T}_{\text {onset }}$ and $\mathrm{T}_{\text {offset }}$ of 20.16 and $-38.8^{\circ} \mathrm{C}$ and -22.2 and $28.6^{\circ} \mathrm{C}$, respectively. The solid fat profile of the oil showed a semi-solid and liquid consistency in the ambient temperature range. The composition, thermal and phase behavior showed that TSO is potentially useful for alimentary, pharmacological, and cosmetological purposes.

KEYWORDS: DSC; Lignoceric acid; Tamarind seed oil; Tamarindus indica; TGA

RESUMEN: Composición, propiedades, estabilidad y comportamiento térmico del aceite de semilla de tamarindo (Tamarindus indica). La composición, estabilidad y comportamiento térmico del aceite de semilla de tamarindo (Tamarindus indica) fueron analizadas con el fin de contribuir al conocimiento de sus potenciales usos. El aceite fue extraído del núcleo de la semilla con hexano y analizado mediante sus principales propiedades físicas, químicas y térmicas mediante espectrometría infrarroja, cromatografía de gases, espectroscopia de masas, calorimetría (DSC) y termogravimetría (TGA). Los resultados mostraron que las semillas del tamarindo tuvieron un contenido de aceite de 3,76 \pm ,20\%, con un índice de saponificación de 174,80 $\pm 9,87 \mathrm{mg} \mathrm{KOH/g}$ y ácidos grasos mayoritarios: Lignocérico $(20,15 \%)$, oleico $(18,99 \%)$, palmítico $(11,99 \%)$ y en cantidades menores los ácidos esteárico, behénico, linoleico y araquídico, entre otros. El análisis mediante TGA y DSC mostró que la temperatura inicial de descomposición del aceite fue de $224,1{ }^{\circ} \mathrm{C}$ en una sola etapa en atmósfera inerte y en atmósfera de aire fue a $218{ }^{\circ} \mathrm{C}$ en tres etapas. El aceite mostró curvas de cristalización y fusión con un solo máximo, iniciándose y finalizando estos cambios de fase a 20,16 y $-38,8^{\circ} \mathrm{C}$, and $-22,2$ y $28,6^{\circ} \mathrm{C}$, respectivamente. Estas propiedades mostraron que el aceite de la semilla de tamarindo tiene potenciales aplicaciones en alimentos y productos farmacológicos y cosméticos.

PALABRAS CLAVE: Aceite de semilla de tamarindo; Ácido lignocérico; DSC; Tamarindus indica; TGA

ORCID ID: Chacón-Fernández MG https://orcid.org/0000-0003-2941-3346, Hernández-Medel MR https://orcid. org/0000-0002-5800-7825, Bernal-González M https://orcid.org/0000-0002-4610-1945, Durán-Domínguez-de-Bazúa MC https://orcid.org/0000-0001-9509-908X, Solís-Fuentes JA https://orcid.org/0000-0002-3974-8812

Citation/Cómo citar este artículo: Chacón-Fernández MG, Hernández-Medel MR, Bernal-González M, DuránDomínguez-de-Bazúa MC, Solís-Fuentes JA. 2019. Composition, properties, stability and thermal behavior of tamarind( Tamarindus indica) seed oil. Grasas Aceites 70 (4), e333. https://doi.org/10.3989/gya.0928182

Copyright: (C2019 CSIC. This is an open-access article distributed under the terms of the Creative Commons Attribution 4.0 International (CC BY 4.0) License. 


\section{INTRODUCTION}

Tamarind, (Tamarindus indica) known in Senegal and India since ancient times, has been considered a multi-purpose plant. Several reports have shown that in addition to the known uses for the pulp as a food, its husk, seeds, leaves, flowers, wood, and tree bark, have diverse potential uses (Rasala et al., 2011; Rao et al., 2015). The food, pharmaceutical, and cosmetic industries are the main receiving sectors, due to the presence of fractions and chemical components of relevant interest to them (De Caluwé et al., 2010; Bhadoriya et al., 2011; Rasala et al., 2011).

In Mexico, the tamarind does not reach an important industrial level or a full and integral use yet, as is also the case in many of the poorest producing regions of this fruit located in Latin America, Asia or sub-Saharan Africa. This tropical plant has been introduced and naturalized in more than 50 countries around the world (Rao et al., 2015).

The flowers, leaves and pulp of the fruit are edible and have important nutrients. The latter has a characteristic sweet-acidic flavor due to the combination of high contents of tartaric acid and reducing sugars. In fact, the tamarind is the largest natural source of this acid widely used in Asian gastronomy (De Caluwé et al., 2010). The fruit is appreciated for its characteristic flavor, sometimes qualified as exotic, because its pulp contains more than 16 volatile components which participate in the conformation of its flavor. The sesquiterpenoide aromadendrene, also found in oils of eucalyptus trees, has been identified as the major volatile constituent (Rasala et al., 2011).

In several countries, the tamarind pulp, aside from being consumed fresh, is used for flavoring and applied as a component of food, for example in jams, sweet sauces and hot sauces, and also as an important ingredient in juices and some soft drinks (El-Siddig et al., 2006; De Caluwé et al., 2010). In most of those applications the seed is discarded as a residue without any value. However, in some countries the seed has been considered a by-product of the industries that process the pulp of the fruit, on the basis that further use has been found for it, derived from some of its properties (Rao et al., 2015). Studies and experimental analyses on the properties of the tamarind seed from the perspective of its potential use are relatively scarce as yet.

The tamarind seed, which includes an external cover or testa $(20-30 \%)$ and the nucleus or endosperm $(70-75 \%)$, contains important compounds such as antioxidants and dyes (Bhadoriya et al., 2011). Its endosperm has proteins of relevant quality, carbohydrates with important functional properties to be used as thickeners and gums, and an interesting lipid fraction from the point of view of some of its properties (Kumar and Bhattacharya, 2008).
The presence in seeds of tannins and some other colorant materials in the test portion, makes its direct consumption inadequate for food (Kumar and Bhattacharya, 2008), but treatments such as soaking and cooking in water make it an edible product, mainly for animals (El-Siddig et al., 2006). Currently, the largest industrialized product of tamarind seed is in powder form which is a material used in the paper, textile and jute industries (Kumar and Bhattacharya, 2008; Rao et al., 2015).

Tamarind seed is the raw material for the elaboration of the polysaccharide jellose, some adhesive products, and for obtaining tannins. Jellose with gelling properties is commercially available as a food additive and is recommended to be used as a stabilizer in ice cream, mayonnaise and cheese, and as an ingredient or agent in pharmaceutical products (El-Siddig et al., 2006).

Concerning the tamarind seed oil (TSO), studies have been reported about some of its properties, such as its fatty acid composition and other basic physicochemical characteristics. Several authors have reported different extraction yields of tamarind seed oil from different producing regions, some of them with relatively high values such as $16.25 \%$ (Morad et al., 1978) although most in a range between $3.0-10.91 \%$ of extracted oil with hexane, ether or mixtures of chloroform/methanol (Adriamanantena, et al., 1983; Ajayi et al., 2006).

The fatty acid composition of tamarind seed oil has been addressed by several authors such as Pitke et al., (1977), Reddy et al., (1979), Morad et al., (1978), Andriamanantena et al., (1983), and Ajayi et al., (2006). However, their results still show important discrepancies in terms of some of its fatty acid components.

The knowledge concerning the effects of heating fats and oils is basic and can be used to determine some of their physical and chemical properties which are important for the evaluation of their potential applications. The complexity and diversity of the thermal profiles and phase behavior of fats and oils are due to the variety of both the triacylglycerides (TAG) and their main fatty acid constituents, FA (Tan and Che Man, 2000; Santos et al., 2004; O'Brien, 2008; Borugadda and Goud, 2014; Solís-Fuentes et al., 2015). However, there are currently no studies aimed at analyzing the thermal and phase properties of the tamarind seed oil that contribute to determine, in a better way, their possible alternative uses.

As it is known, information on the thermal stability of vegetable fats and oils is essential for the identification of their potential uses, and many of the most important properties of fats and oils are related to their phase behaviour, mainly in the solid/ liquid and liquid/solid transitions. This behavior is dependent on, among other variables, the composition of fatty acid and triacylglycerides, as well as the 
polymorphic properties assumed in the solid phase (O’Brien, 2008; Roos, 2016).

In order to contribute to tamarind seed oil knowledge and to visualize alternatives uses within the perspective of an integral use of tamarind, the objective of this paper was to study the seed of the tamarind and characterize its extracted oil by infrared spectroscopy and fatty acid composition, as well as analyzing the thermal stability and phase behavior of the tamarind seed oil by thermogravimetry and differential scanning calorimetry.

\section{MATERIALS AND METHODS}

\subsection{Obtaining tamarind samples}

Samples of tamarind fruits (Tamarindus indica) chosen according to their physiological maturity, which is in terms of the color and texture of their skin and pulp, were acquired in a local market near the production area of this product, in the municipality of Paso de Ovejas $\left(19^{\circ} 17^{\prime}\right.$ north latitude, $96^{\circ} 26^{\prime}$ west longitude), in the central coastal region of the State of Veracruz in Mexico. The samples were evaluated in terms of the number of seeds per pod, the masses and percentages of the husk, pulp, and seed, and kernel of the seed. For the latter, two samples of five tamarind fruits each were separated and weighed in their main portions in an analytical balance and the average mass and percentage of each portion in the total of the fruit were estimated.

\subsection{Physicochemical analysis of the seed nucleus}

The official analysis techniques were used to determine the moisture, ash, crude fiber and crude fat (Horwitz, 1995) contained in the nuclei of the tamarind seed.

\subsection{Extraction, purification, physical and chemical characterization of seed oil}

The oil was extracted from the dehydrated kernels of the tamarind seed (with approximately 10\% moisture) using hexane as a solvent in a Soxhlet apparatus and the resulting micelle was processed in a rotary evaporator for oil recovery. The raw TSO was purified by a modification of the Wesson method described in Solís-Fuentes et al., (2015). The purified oil was deposited in glass containers and stored under refrigeration conditions $\left(-5^{\circ} \mathrm{C}\right)$ and protected from light, until analysis and/or further processing. The purified TSO was evaluated by a group of untrained judges, in terms of the perception of its consistency at room temperature, color, odor and taste. The oil was physicochemically analyzed to determine its refractive index, free fatty acids, acidity index, and saponification index using the official analysis techniques (Horwitz, 1995).

\subsection{Infrared spectroscopy (FT-IR) of tamarind seed oil}

A Perkin-Elmer Spectrum Two FT-IR spectrophotometer was used. The data were processed with the help of the Spectrum software. In the case of the liquid sample, its IR analysis did not require any previous preparation.

\subsection{Analysis of the fatty acid composition of tamarind seed oil}

Fatty acid methyl esters were prepared by saponification of purified tamarind seed oil and an acidcatalyzed methylation, using an alcoholic solution of $2.5 \% \mathrm{KOH}$ and a methanol solution to $2 \% \mathrm{H}_{2} \mathrm{SO}_{4}$. (Anu and Rao, 2001).

For the analysis of the fatty acids constituents of the acylglycerols of TSO, a gas chromatograph Shimadzu was used, equipped with a column of polydimethylsiloxane with $5 \%$ phenyl, ZB-5MSi, of $30 \mathrm{~m} \times 0.25 \mathrm{~mm} \times 0.25 \mu \mathrm{m}$, coupled to a Shimadzu mass spectrometer provided with a full spectrum scan detector (SCAN) of 50 to $500 \mathrm{-m} / \mathrm{z}$. A mixture of fatty acid standards (FAME mix 37 SUPELCO) was used to support the identification of the methyl esters in the sample. The operating conditions in the chromatograph were: an initial temperature of $100{ }^{\circ} \mathrm{C}$ for $5 \mathrm{~min}$, with a heating rate of $4^{\circ} \mathrm{C} / \mathrm{min}$ up to $250^{\circ} \mathrm{C}$ for $15 \mathrm{~min}$; the carrier gas was helium at $0.8 \mathrm{~mL} / \mathrm{min}$, the injector temperature was $250^{\circ} \mathrm{C}$ and, an ionization source of electronic impact was used.

\subsection{Thermal stability of TSO}

The thermal stability of the TSO was analyzed by thermogravimetry in atmospheres of nitrogen and air in a TGA Q5000 IR (TA Instruments), using a sample holder of alumina. The changes in mass were monitored in a working interval of 25 to $1000{ }^{\circ} \mathrm{C}$ to obtain the TG and DTG data and graphs. The capture of the data in an ASCII code made analysis possible and the results were graphically edited in the Origin software (OriginLab, 2007).

\subsection{Phase behavior of TSO}

TSO samples were analyzed in a TA Instruments DSC Q2000 differential scanning calorimeter equipped with a TA Universal Analysis data analysis station. The purge gas was nitrogen at a flow of $50 \mathrm{~mL} / \mathrm{min}$. The instrument was calibrated with Indium (melting point $156.6{ }^{\circ} \mathrm{C} ; \mathrm{DH}_{\mathrm{f}}, 28.45 \mathrm{~J} / \mathrm{g}$ ). Samples between 2 and $12 \mathrm{mg}$ were weighed in a thermobalance (TA instruments) in aluminum SFI capsules with a precision of $\pm 0.1 \mathrm{mg}$ and then hermetically sealed. An empty and sealed capsule was used as reference. Each of the samples was heated 
up to $90^{\circ} \mathrm{C}$ with an isotherm of 5 min with the aim of destroying its thermal history. To analyze the thermal behavior of the oil, the following conditions were used: Crystallization profile: the sample was heated up to $90{ }^{\circ} \mathrm{C}$ for $5 \mathrm{~min}$ and cooled to $5^{\circ} \mathrm{C} /$ min to $-80{ }^{\circ} \mathrm{C}$ to record the crystallization profile, crystallization enthalpies, and the onset and offset temperatures of the phase changes.

Fusion profile: the sample was heated from -80 to $5^{\circ} \mathrm{C} / \mathrm{min}$ up to $90^{\circ} \mathrm{C}$, and the melting profile, the enthalpy and the onset and offset temperatures of the phase changes were recorded.

\subsection{Solid/Liquid relationships of TSO}

The amount of solids in the oil samples as a function of temperature were calculated based on the experiments in the DSC, according to the methodology outlined by Lambelet and Raemy (1983) and with the use of the computation package Origin (OriginLab, 2007). Since the contents of solid fat depend on the temperature, these values can be presented as a function of it. The values for the solid content can be expressed, by sequential integration of the melting curve, by means of equation 1 . The partial areas of the thermograms were calculated and correlated with the percentage of solids considering that at $-80{ }^{\circ} \mathrm{C}$ the oil samples are practically $100 \%$ solid.

$$
\% \operatorname{Solids}(T)=\frac{\int_{T 0}^{T} H(T) d t}{\int_{T 0}^{T 1} H(T) d t}
$$

\section{RESULTS AND DISCUSSION}

\subsection{The fruit of tamarind and its constituent portions}

The samples of the physiologically mature tamarind fruit were pods with brown skin rind and rust colored pulp with an average mass of $16.37 \mathrm{~g}$ per fruit. The mass of each anatomical constituent part of the pods was on average $21.61 \%$ husk, $58.0 \%$ pulp and $20.34 \%$ seeds. The fruit had between 3 to 4 seeds for each pod unit.

\subsection{Physicochemical analysis of the seed nucleus}

The tamarind seeds had an average mass of $0.87 \mathrm{~g} / \mathrm{seed}$ with a bright, dark color. They were constituted by an external cover or testa and a nucleus or endosperm; the latter represented, on average, $77.73 \pm 3.56 \%$ of the total seed mass. Table 1 presents some of the main physical and chemical characteristics of the fruit, seeds and oil extracted from tamarind. The chemical analysis of the endosperm
TABLE 1. Physical and chemical characteristics of the fruit and oil extracted from the tamarind seed

\begin{tabular}{lc}
\hline Characteristic & Value \pm SD $^{\mathrm{a}}$ \\
\hline Tamarind fruit & \\
Average mass, g & $16.37 \pm 4.31$ \\
Husk, \% & $21.61 \pm 4.90$ \\
Pulp, \% & $58.00 \pm 2.10$ \\
Seeds, \% & $20.34 \pm 2.50$ \\
Seeds, average number & $3.81 \pm 1.60$ \\
Tamarind seed & \\
& \\
Moisture, \% & $11.61 \pm 0.33$ \\
Nucleus of the seed, \% & $77.73 \pm 3.56$ \\
Ash, \% db & $3.71 \pm 0.27$ \\
Crude fiber, $\%$ db & $2.09 \pm 0.51$ \\
Crude fat, $\%$ db & $3.76 \pm 0.20$ \\
Tamarind seed oil & \\
Consistency, $25^{\circ} \mathrm{C}$ & Liquid \\
Color: & Amber \\
Odor: & Characteristic \\
Taste: & No taste \\
Refractive index & 1.465 \\
Saponification value, mg KOH/g & $174.80 \pm 9.87$ \\
Free fatty acids, \% & $3.12 \pm 0.24$ \\
Acidity index, mg oleic acid/g & $6.22 \pm 0.47$ \\
\hline
\end{tabular}

a: Average values of two determinations \pm standard deviation

of the tamarind showed moisture content of $11.61 \pm 0.33 \%$. The main fractions were the carbohydrates and the proteins accounting for around $90 \%$ of the dry solid. Its contents of ashes, crude fiber and crude fat were of $3.71 \pm 0.27,2.09 \pm 0.509$, and $3.76 \pm 0.20 \%$ (d.b.), respectively.

\subsection{The oil of the tamarind seed}

The refined oil of the tamarind seed had a liquid consistency under environmental conditions (around $25^{\circ} \mathrm{C}$ ), a light amber color, a characteristic smell, and an undefined flavor.

TSO had a refractive index of 1.465 , saponification and acidity indices of $174.80 \pm 9.87 \mathrm{mg} \mathrm{KOH} / \mathrm{g}$ and $6.215 \pm 0.47 \mathrm{mg}$ oleic acid/g, respectively; and a content of $3.12 \pm 0.24 \%$ of free fatty acids. These values are close to those reported by Pitke et al., (1977) and Adewuyi et al., (2011). Table 1 summarizes the physical and chemical characteristics of this oil.

\subsection{FTIR spectrum of tamarind seed oil}

Figure 1 shows the FTIR spectra of TSO. Figure 1(a) corroborates that the hexane fraction extracted from the tamarind seed corresponds to a 
(a)

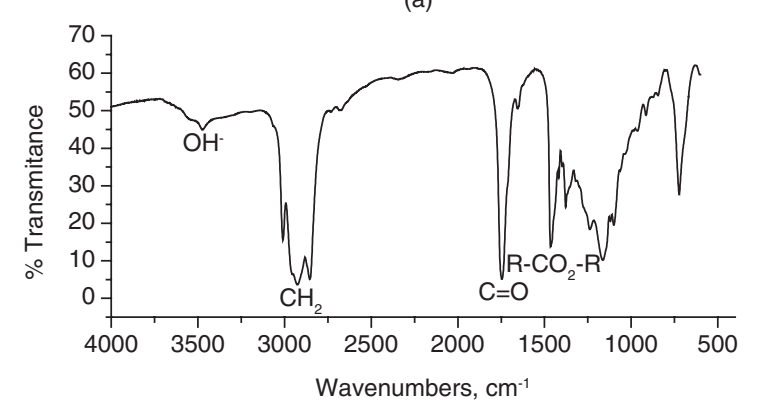

(b)

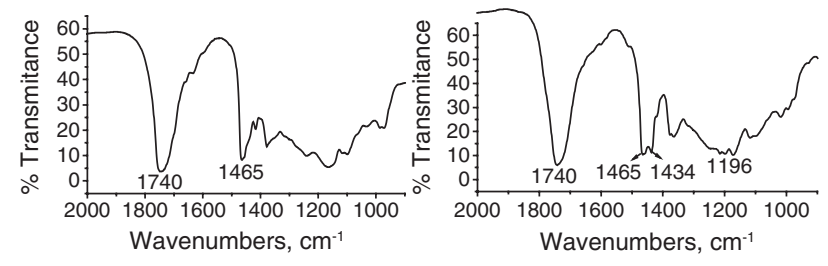

FIGURE 1. FTIR spectra of (a) refined tamarind seed oil; (b) main signals from $2000-900 \mathrm{~cm}^{-1}$ of purified tamarind seed oil; (c) main signals from $2000-900 \mathrm{~cm}^{-1}$ of methyl esters of fatty acids from tamarind seed oil.

vegetable oil. The peaks and shoulders provide information about their structure and functional groups. In the region of high frequencies (around $3465 \mathrm{~cm}^{-1}$ ), the absorption corresponding to the hydroxyl groups, including water (residual moisture in the analyzed sample), is identified; at lower frequencies, the signals (3025-2838 $\left.\mathrm{cm}^{-1}\right)$ of the methyne and methylene groups (from the double bonds and the aliphatic chains of the triacylglycerols) and methyl groups (methyl terminal) are identified.

At the center of the spectrum near $1753 \mathrm{~cm}^{-1}$ there is a strong signal corresponding to the carbonyl groups due to the ester bonds of fatty acids and glycerol of the triacylglycerols of the oil, including free acid carbonyl bonds from the free fatty acids present in the sample analyzed. Finally, the region of low frequency between $1500-800 \mathrm{~cm}^{-1}$, is considered the area where a group of signals appears due to the absorption of characteristic groups of lipid compounds, including double bonds, conjugated dienes, etc. (Shahidi and Wanasundara, 2002).

The FTIR analysis was also used together with the thin layer chromatography, as a complement to corroborate the progress and result of the methylation process of the tamarind seed oil, prior to the determination of its composition. Figures $1 b$ and 1c present the FTIR spectra of both the tamarind seed oil and the oil after having been derivatized to their corresponding methyl esters of the fatty acids. These figures show the frequency range which goes from 1500 to $1000 \mathrm{~cm}^{-1}$, and covers the region considered as characteristic of each vegetable oil $\left(1500-800 \mathrm{~cm}^{-1}\right)$. The peak at $1434 \mathrm{~cm}^{-1}$ corresponds to the asymmetric stretching of $-\mathrm{OCH}_{3}$ and is present in the spectrum of fatty acid methyl esters of tamarind seed, but not in the oil spectrum. This peak is typical of a mixture of methyl esters of fatty acids. (Shahidi and Wanasundara, 2002; Rabelo et al., 2015).

\subsection{Fatty acid composition of TSO}

Table 2 presents the results of the fatty acid analysis of TSO made by gas chromatography and mass spectroscopy. The composition of this oil has a higher content of saturated fatty acids, with $63.95 \%$ of the total; highlighting a high content of longchain saturated FAs: lignoceric acid with $20.15 \%$, palmitic $(11.91 \%)$ and stearic $(7.63 \%)$, followed by behenic $(7.57 \%)$ and arachidic $(5.33 \%)$. The saturated medium-chain fatty acids, caprylic, capric, azelaic and lauric, as well as myristic, margaric and long-chain tricosylic acid, were present in this tamarind seed oil with individual percentages lower than $2 \%$ each.

TSO fatty acids are $32.39 \%$ unsaturated, with the majority being oleic acid (18.99\%), linoleic $(4.94 \%)$, and paulinic acid (4.22\%). Also, 9-cis-hexadecenoic acid (palmitoleic 1.95\%) and 7-cis-hexadecenoic acid $(0.45 \%)$, were present. Some other complex fatty acids were also identified: Epoxy acids, oxo acid, and hydroxylated and branched fatty acids, whose content as a whole was $7.48 \% .3 .65 \%$ of the total fatty acids could not be identified.

Different reports found on the fatty acid composition of tamarind seed oil differ greatly from one another, both considering the presence of different fatty acids in the oil, as well as in the percentages assigned to each of them. The results obtained in the present work are closely related, but with some differences, to those reported by Pitke et al., (1977), which include palmitic (14.8\%), stearic $(5.9 \%)$, oleic $(27.0 \%)$, linoleic $(7.5 \%)$, linolenic $(5.6 \%)$, arachidic $(4.5 \%)$, behenic $(12.2 \%)$, and lignoceric $(22.3 \%)$ acids.

According to the results of this work, the TSO does not contain short-chain fatty acids $(<6 \mathrm{C})$ and the percentages of saturated fatty acids classified according to chain length were medium-chain fatty acids (MCSFA, between 6C and 12C): 2.95\%, long-chain saturated FA (LCSFA, between 14C and 20C): $30.73 \%$ and very-long-chain saturated FA (VLCSFA,> 20C): $28.46 \%$. The unsaturated fatty acids in the oil were all of long-chain.

An interesting feature of the composition of the TSO is its high content of LCSFA and mainly VLCSFA. The saturated fatty acids with aliphaticchain $>20 \mathrm{C}$, that is arachidic, behenic, tricosylic, and lignoceric acids, were $33.79 \%$ in total.

The role of long- and very-long-chain saturated fatty acids in nutrition and human health is not fully established yet, but it is known that very-long-chain saturated fatty acids (VLSFA) play an important 
TABLE 2. Fatty acid composition of tamarind seed oil

\begin{tabular}{|c|c|c|c|}
\hline Fatty acid & Delta notation & Retention time & $\%$ Area \\
\hline Caprylic & $8: 0$ & 8.174 & 0.23 \\
\hline Capric & 10:0 & 14.801 & 0.08 \\
\hline 8-oxooctanoic & $8-\mathrm{O}=8: 0$ & 15.090 & 0.47 \\
\hline 9-oxo nonanoic & $9-\mathrm{O}=9: 0$ & 18.583 & 1.18 \\
\hline Azelaic & 8-COOH-8:0 & 22.246 & 0.55 \\
\hline Lauric & $12: 0$ & 21.476 & 0.44 \\
\hline Tridecylic & $13: 0$ & 24.588 & 0.22 \\
\hline Cis-7-Hexadecenoic & 16:1-delta-7c & 26.795 & 0.41 \\
\hline Myristic & $14: 0$ & 27.544 & 1.44 \\
\hline Pentadecylic & $15: 0$ & 30.335 & 0.85 \\
\hline Palmitoleic & 16:1-delta-9c & 32.410 & 1.95 \\
\hline Palmitic & $16: 0$ & 33.222 & 11.91 \\
\hline cis-10-Heptadecenoic & 17:1-delta-10c & 34.961 & 0.26 \\
\hline Margaric & $17: 0$ & 35.542 & 0.95 \\
\hline Linoleic & 18:2-delta-9c, 12c & 37.567 & 4.94 \\
\hline Oleic & 18:1-delta-9c & 37.718 & 18.99 \\
\hline Stearic & $18: 0$ & 38.102 & 7.63 \\
\hline Oxiraneoctanoic, 3-octyl & $9,10-\mathrm{O}-18: 0$ & 41.549 & 1.78 \\
\hline Paulinic & 20:1-delta-13c & 42.036 & 4.22 \\
\hline Arachidic & $20: 0$ & 42.604 & 5.33 \\
\hline 6-Hexadecenoic acid, 7-methyl & 7-Me-16:2-delta-6t & 43.197 & 1.62 \\
\hline Octadecanoic, 9,10-dihydroxy & R9,R10-di-OH-18:0 & 44.604 & 2.43 \\
\hline Behenic & $22: 0$ & 47.809 & 7.57 \\
\hline Tricosylic & $23: 0$ & 51.049 & 0.74 \\
\hline Lignoceric & $24: 0$ & 55.933 & 20.15 \\
\hline Non identified & & & 3.65 \\
\hline Total saturated fatty acids & & & 63.95 \\
\hline MCSFA & & & 2.95 \\
\hline LCSFA & & & 32.32 \\
\hline VLCSFA & & & 28.46 \\
\hline Total unsaturated fatty acids & & & 32.39 \\
\hline
\end{tabular}

MCSFA: medium-chain saturated FA; LCSFA: long-chain saturated FA; VLCSFA: very-long-chain saturated FA

role in the structure, cellular and organic functioning of the body. The VLSFA are major components of ceramides and sphingomyelins, lipids formed by a main chain of sphingosine with an acylated FA, often saturated (Quehenberger et al., 2010). Recent studies have analyzed the role of circulating levels of very-long-chain fatty acids on some metabolic and cardiovascular diseases (Fretts et al., 2014; Lemaitre et al., 2014, 2015). The determining causes of high levels of VLSFA can be either dietary or metabolic. VLSFA such as behenic, arachidic, and lignoceric acids are found in only some foods such as peanuts, macadamia nuts, and canola oil, and their consumption has been associated with high levels of these FA in plasma.

Lemaitre et al., (2015) found an association of higher levels of VLSFA with plasma phospholipids with a lower risk of incidence of diabetes, which may be mediated by lower levels of triglycerides and palmitic acid phospholipids in plasma. Fretts et al., (2014) and Lemaitre et al., (2014) determined inverse associations of VLSFA with an incident of atrial fibrillation and an incidental sudden cardiac arrest.

On the other hand, as ceramides are the base molecules of sphingolipids, they are very abundant 
in the lipid bi-layer of cell membranes and their exocytosis to the intercellular space allows them to function as the cementing substance due to the amphiphilic chemical structure in the stratum corneum, one of the four different sublayers of skin epidermis (Sahle et al., 2015). The fact that ceramides usually contain very-long-chain fatty acids such as lignoceric, nervonic, or cerebronic acids, has led to the consideration that, particularly lignoceric acid, has an interesting potential use in the elaboration of dermatological oils and medicines, products that have been developed up to now, mainly based on behenic acid, due to its softening and moisturizing action on the skin (Sahle et al., 2015).

Lignoceric acid is found in trace amounts in almost all edible vegetable oils, with some exceptions, such as peanut oil, whose content is close to $1 \%$. It is contained in higher amounts in sources with no commercial production. Some wild plant seeds have been reported with high content of long-and very-long-chain saturated fatty acids, in which lignoceric acid is present in high percentages (Spitzer et al., 1990). Akhtar et al., (1986) reported that some seeds of the Cruciferae family, such as Erysimum perofskianum, have lignoceric acid in their oils up to $23.2 \%$; Hondelmann and Radatz (1982) found that Lunaria annua oil has $21 \%$ of this FA; and Sultana and Gulzar (2012) found that this fatty acid is present in the Adenanthera pavonina oil at a level of $20.24 \%$.

The tamarind seed, being a residue of the consumption and industrialization of this fruit with a wide acceptance in the world, acquires an interesting role as a potential source of oil with longand very-long-chain fatty acids and especially as a source of lignoceric acid, identified, as noted earlier, with important functional properties which are protective of the health of the human organism in regards to the cardiovascular, endocrine and skin systems.

\subsection{Thermal stability of TSO}

When vegetable fat and oils are exposed to high temperatures, a process of deterioration occurs. However, these oils sometimes have natural antioxidants that tend to increase the stability of the products made with them. The stability of the oil to heat treatment is an aspect of great importance as is the degree and speed of decomposition of the constituents of the oil. It depends on many factors that include both the treatment conditions (time, temperature level, presence of oxygen, water and other constituents, etc.) and the fatty acid and acylglyceride compositions of the oil.

Figure 2 shows the TG and DTG curves of TSO in a nitrogen atmosphere and allows the decomposition process of the oil sample to be analyzed by

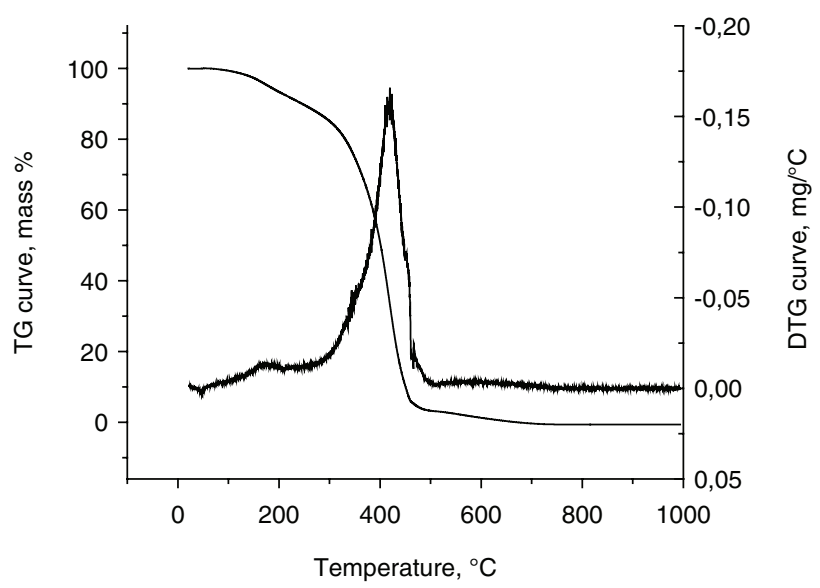

FIGURE 2. TG and DTG curves of tamarind seed oil in nitrogen atmosphere.

this thermal treatment by heating it from $25^{\circ} \mathrm{C}$ to $1000{ }^{\circ} \mathrm{C}$. The curves show a process completed in only two stages. The first one is attributed to the elimination of residual water and volatile oil materials appreciated in the characteristic aroma of the TSO, as was found in the FTIR analysis. This stage had a maximum decomposition speed of 0.014 $\mathrm{mg} /{ }^{\circ} \mathrm{C}$ at $166.8^{\circ} \mathrm{C}$, and a total loss in mass of $6.94 \%$, starting at $108.8^{\circ} \mathrm{C}$ and ending at $223.16^{\circ} \mathrm{C}$.

The second stage corresponded to the decomposition of the constituent acylglycerols of the TSO, which, as has been identified by other researchers, occurs in an inert atmosphere, around an interval that was from 220 to $420{ }^{\circ} \mathrm{C}$ (Melzer et al., 2013). This stage of tamarind seed oil decomposition was observed from 224.1 to $509{ }^{\circ} \mathrm{C}$, with a maximum speed of $0.163 \mathrm{mg} /{ }^{\circ} \mathrm{C}$ at $418.42{ }^{\circ} \mathrm{C}$, and with a mass loss along this stage of $90.48 \%$. The global residue obtained was $2.58 \%$.

The main data of the thermogravimetric analysis of TSO are presented in Table 3, and Figure 3 shows the TG and DTG curves of the oil sample in an air atmosphere. In this case the decomposition process includes a more complex set of reactions due to the presence of oxygen from the air and in addition to the first stage corresponding to the loss of residual moisture and volatile compounds, whose maximum peak occurs at $145.41{ }^{\circ} \mathrm{C}$. The whole decomposition process of the neutral lipids of TSO required three additional stages, from which the first one started at $218{ }^{\circ} \mathrm{C}$ and ended at $361.25^{\circ} \mathrm{C}$, with a mass loss of $22.79 \%$. The next stage occurred with a maximum decomposition speed of $0.079 \mathrm{mg} /{ }^{\circ} \mathrm{C}$ at 417.63 , finishing at $477.91{ }^{\circ} \mathrm{C}$. Finally, one last stage was present, which ended at $616^{\circ} \mathrm{C}$. The residual mass resulting from the thermal and oxidative decomposition of the TSO was $4.78 \%$. This thermal behavior of decomposition of TSO is similar 
TABLE 3. Main data of thermogravimetric analysis of tamarind seed oil

\begin{tabular}{|c|c|c|c|c|c|c|c|c|}
\hline \multirow[b]{2}{*}{ Stage } & \multicolumn{4}{|c|}{ Nitrogen atmosphere } & \multicolumn{4}{|c|}{ Air atmosphere } \\
\hline & $\Delta \mathrm{T}_{\text {decom }}{ }^{\circ} \mathrm{C}$ & $\mathbf{T}_{\text {peak }}{ }^{\circ} \mathbf{C}$ & $-\Delta_{\text {mass }} \%$ & $\mathbf{R}_{\text {decom }} \mathbf{m g} /{ }^{\circ} \mathrm{C}$ & $\Delta \mathbf{T}_{\text {decom }}{ }^{\circ} \mathrm{C}$ & $\mathbf{T}_{\text {peak }}{ }^{\circ} \mathbf{C}$ & $-\Delta_{\text {mass }} \%$ & $\mathbf{R}_{\text {decom }} \mathrm{mg} /{ }^{\circ} \mathrm{C}$ \\
\hline 1 & $108.88-223.16$ & 166.80 & 6.94 & -0.014 & $93.88-217.36$ & 145.41 & 6.58 & -0.008 \\
\hline 2 & $224.10-509.07$ & 418.42 & 90.48 & -0.163 & $218.00-361.25$ & 322.27 & 22.79 & -0.019 \\
\hline 3 & & & & & $362.10-477.91$ & 417.63 & 50.78 & -0.079 \\
\hline 4 & & & & & $478.50-600.16$ & 544.02 & 15.07 & -0.017 \\
\hline Total & $108.88-509.07$ & & 97.42 & & $93.88-600.16$ & & 95.22 & \\
\hline Residue & & & $2.58 \%$ & & & & 4.78 & \\
\hline
\end{tabular}

Value of temperature $(\mathrm{T})$ and rate $(\mathrm{R})$ in the Table represents the means of two determinations, with $\mathrm{SD}<1.0^{\circ} \mathrm{C}$ and $\mathrm{SD}<0.001 \mathrm{mg} /{ }^{\circ} \mathrm{C}$, respectively, from Fig. 2 and $3 . \Delta \mathrm{T}_{\text {decom }}$ : Decomposition interval; $\mathrm{T}_{\text {peak }}$ : Temperature of the maximum decomposition rate; $-\Delta_{\text {mass }}$ : Percentage of mass loss; $\mathrm{R}_{\text {decom }}$ : Decomposition rate

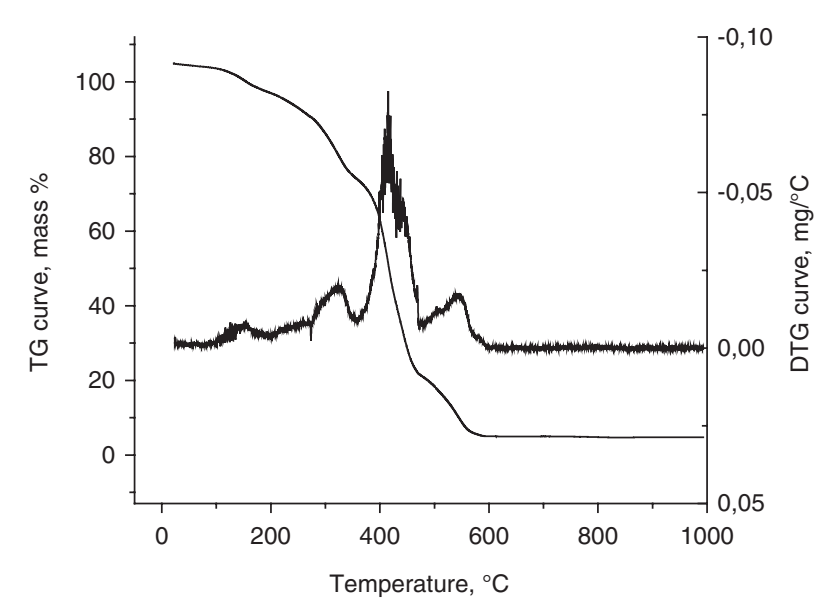

FIGURE 3. TG and DTG curves of tamarind seed oil in air atmosphere.

to that reported by Santos et al., (2004) for the thermal decomposition, in air, of several vegetable oils (rapeseed, sunflower, rice, corn, olive and soybean) in which the said process was constituted by three decomposition stages at temperatures between $200{ }^{\circ} \mathrm{C}$ and $600{ }^{\circ} \mathrm{C}$.

\subsection{TSO phase behavior}

The phase behavior of TSO was analyzed by DSC. Figure 4 shows the crystallization and fusion curves obtained at $5{ }^{\circ} \mathrm{C} / \mathrm{min}$. Both curves are very simple with a single transition peak. The oil began to crystallize by cooling at $20.16^{\circ} \mathrm{C}$ and ended at $-38.2^{\circ} \mathrm{C}$, with a maximum solidification close to $2.5^{\circ} \mathrm{C}$. The enthalpy of crystallization was $-27.35 \mathrm{~J} / \mathrm{g}$. On the other hand, the onset and offset melting temperatures of TSO were $-22.2{ }^{\circ} \mathrm{C}$ and $28.6{ }^{\circ} \mathrm{C}$, respectively, with a maximum at $15.4^{\circ} \mathrm{C}$, and a $20.26 \mathrm{~J} / \mathrm{g}$ of transition heat. The melting behavior of TSO resembles that of coconut oil and one of the liquid fractions (RFL) of sapote Mamey seed oil; the first with a melting range from -25.8 to 25.30 (Tan and Che Man, 2000) and

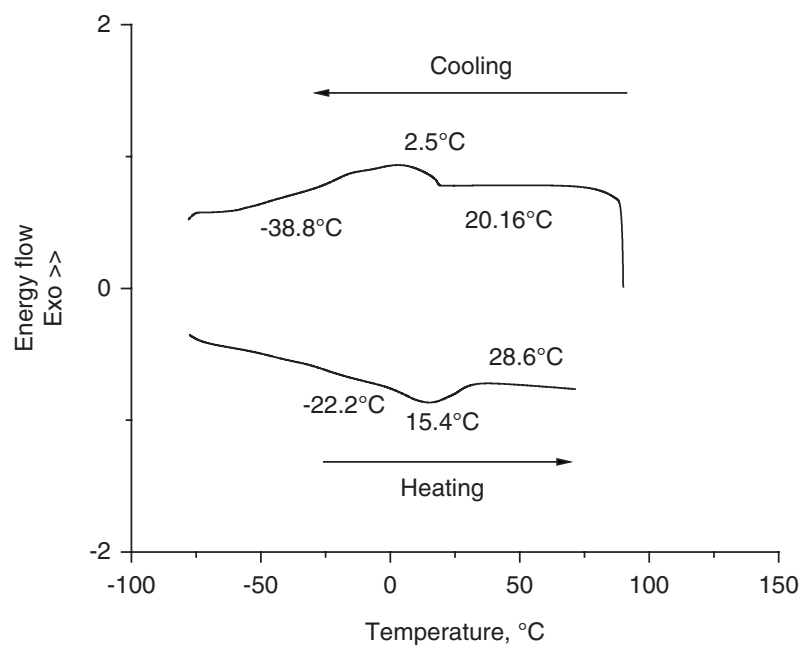

FIgURE 4. Crystallization and fusion curves of tamarind seed oil.

the second from 22.1 to 21.0 (Solís-Fuentes et al., 2015). In both cases a simple melting curve with the predominance of one maximum melting peak was observed.

\subsection{Solid/liquid relationships}

Figure 5 shows the solid profile of TSO, which provides data regarding the levels of the S/L ratio of the oil at various temperatures. The figure includes the characteristic intervals of the refrigeration, environmental and corporal temperatures that serve to understand the liquidity and functionality of the mixtures of triacylglycerides. These mixtures are constituents of the fat fraction under these temperature conditions.

In relation to body temperature, for example, for edible fats and oils products, these data on oil phase behavior can give valuable indications about their palatability, gumminess, workability, and general behavior. The same happens with refrigeration, environmental, or higher temperatures. 


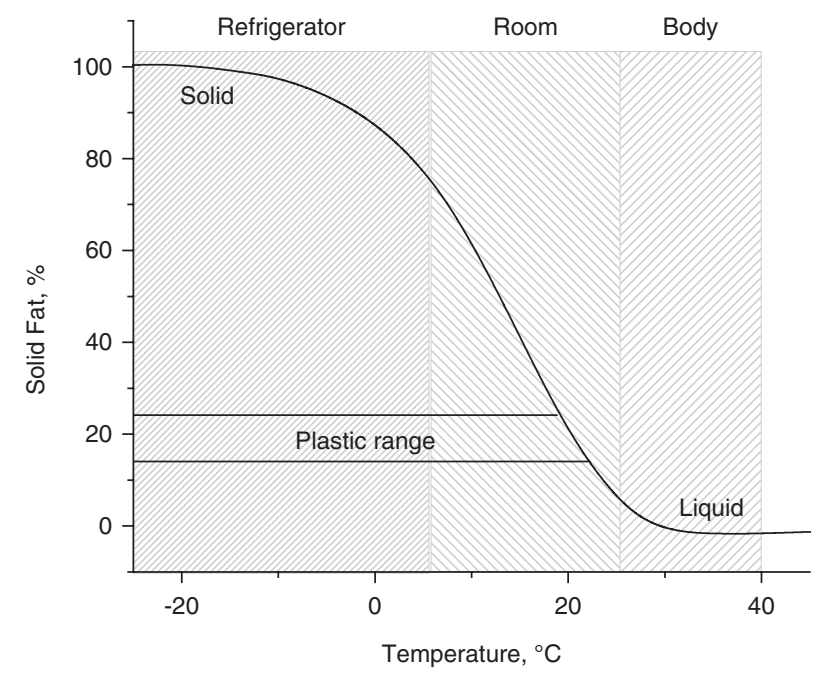

FIGURE 5. Solid/liquid relationships of tamarind seed oil in the characteristic refrigeration, environmental, and body temperature ranges.

The most important factor in the consistency of fats and oils is the proportion of the solid and liquid phases; they become firmer as the solid content increases. The solid-fat profile shows the temperature range in which the oil changes its consistency and therefore, transits from the solid phase to the liquid one (or vice versa), including the temperature region in which it has the ability to be molded, called the plastic range (between 15 and $25 \%$ of solids). There is an interval where the fat or oil has the best consistency to be worked on. The solid profile also shows the lowest temperature at which the oil is totally liquid, and if the profile of solids is flat (with a wide plastic range) or if the profile has a steep slope. In this sense, the TSO has a melting range of $50.8^{\circ} \mathrm{C}$ (from -22.2 to $28.6{ }^{\circ} \mathrm{C}$ ). At temperatures higher than 28.6 , the oil is completely liquid, with a total absence of crystalline nuclei. Said range mainly includes the temperatures considered as environmental. Those that correspond from the refrigeration conditions to close to the body temperature. From $5{ }^{\circ} \mathrm{C}$ and lower, the percentage of solids in TSO is greater than $78 \%$.

Within the range of temperatures that are considered environmental, around 5 to $25^{\circ} \mathrm{C}$, the percentage of solid fat in the liquid oil fluctuates from 78 to $5.15 \%$. Thus, TSO in this environmental temperature range is perceived as a semi-solid to liquid consistency as the temperature increases. In the range of body temperatures the oil shows a gradual decrease in the solid content until it reaches zero at $28.6^{\circ} \mathrm{C}$.

As shown in Figure 5, the plastic range of the TSO is very short and occurs at a temperature 18.75 and $22.18{ }^{\circ} \mathrm{C}$. The slope of the solid fat profile of this oil is not flat and neither is it notoriously deep. As is known, the plasticity and consistency of an edible fat and oil depends not only on the quantity, but also on the size, shape, predominant polymorphic form and distribution of the solid material, as well as the development of crystalline nuclei capable of withstanding high temperatures to serve as initiator nuclei for the growth of crystals.

Some of the most critical factors in the behavior of products made with fats and oils refer to these two properties; for example, butter, margarine and spreads depend on the consistency of the fat portion and its ability to be spread over a slice of bread. A wide plastic range and a soft consistency are required for the fillers and margarines used for thin rolling at refrigerater temperatures. This same plasticity is necessary for the handling of shortenings in ice cream and aerated milkshakes (O'Brien, 2008). So, the consistency and plasticity of a fat product should be known for a range of temperatures.

According to Figure 5, the solid profile and consistency of TSO is closer to that presented by the frying shortenings than those of confectionary fats and plastic fats or, on the other end, liquid shortenings (O'Brien, 2008).

\section{CONCLUSIONS}

According to the results obtained in this work, the oil extracted from the tamarind seed has a refractive index of 1.465 , and a saponification value of $174.8 \mathrm{mg} \mathrm{KOH} / \mathrm{g}$. The major FA of the TSO are: Lignoceric, oleic, palmitic, stearic, and behenic acids, with the presence of arachidic, linoleic, and paulinic acids, among others in smaller quantities.

The high content of saturated fatty acids of longand very-long-chain acids is notable, and whose concentration encompasses about $60 \%$ of the total, of which lignoceric acid represented more than a third.

The TSO showed an initial decomposition temperature of its triacylglycerol components of $224.1^{\circ} \mathrm{C}$ in inert atmosphere and $218^{\circ} \mathrm{C}$ in air atmosphere. The analysis of the phase behavior of the oil showed that the transition to the solid phase starts at $20.16^{\circ} \mathrm{C}$ and the transition to the liquid phase ends at $28.6^{\circ} \mathrm{C}$.

The $\mathrm{S} / \mathrm{L}$ ratios showed that at temperatures considered environmental, the oil has a semi-solid and liquid consistency within that temperature range.

The composition, thermal stability and phase behavior presented by the tamarind seed oil make it potentially usable in applications in the food industry, Pharmacology, and cosmetology.

\section{ACKNOWLEDGEMENTS}

The authors thank the Institute of Materials Research of the UNAM, Mexico for its support in carrying out the calorimetric analysis included in this work. They would also like to thank Prof. Siegfried Erich Haid for revising and correcting the manuscript. 


\section{Support and financing}

This work was carried out with the normal financial support of Universidad Veracruzana and Universidad Nacional Autónoma de México.

\section{REFERENCES}

Adewuyi A, Oderinde RA, Rao BVSK, Prasad RBN, Nalla M. 2011. Proximate analysis of the seeds and chemical composition of the oils of Albizia saman, Millettia griffonianus and Tamarindus indica from Nigeria. Annals: Food Sci. Technol. 12, 123-129.

Ajayi IA, Oderinde RA, Kajogbola DO, Uponi JI. 2006. Oil content and fatty acid composition of some underutilized legumes from Nigeria. Food Chem. 99, 115-120. https:// doi.org/10.1016/j.foodchem.2005.06.045

Akhtar KA, Bokadia MM, Mehta BK, Batra KA. 1986. Chemical characterization and antimicrobial activity of some seed oils of Cruciferae family. Grasas Aceites 37, $148-151$.

Andriamanantena RW, Artaud J, Gaydou EM, Iatrides MC, Chevalier JL. 1983. Fatty acid and sterol compositions of malagasy tamarind kernel oils. J. Am. Oil Chem. Soc. 60, 1318-1321. https://doi.org/10.1007/BF02702108

Anu SJ, Rao JM. 2001. Oxanthrone esters from the aerial parts of Cassia kleinii. Phytochemistry 57, 583-585. https://doi. org/10.1016/S0031-9422(01)00114-5

Bhadoriya SS, Ganeshpurkar A, Narwaria J, Rai G, Jain AP. 2011. Tamarindus indica: Extent of explored potential. Pharmacogn. Rev. 5, 73-81. https://doi.org/10.4103/09737847.79102

Borugadda VB, Goud VV. 2014. Thermal, oxidative and low temperature properties of methyl esters prepared from oils of different fatty acids composition: A comparative study. Thermochim. Acta 577, 33-40. https://doi.org/10.1016/j.tca. 2013.12.008

Caluwé E de, Halamová K, Van Damme P. 2010. Tamarindus indica L.: A review of traditional uses, phytochemistry and pharmacology. Afrika Focus 23, 53-83. https://doi.org/ 10.21825/af.v23i1.5039

El-Siddig K, Gunasena HPM, Prasa BA, Pushpakumara DKNG, Ramana KVR, Vijayanand P, Williams JT. 2006. Tamarind - Tamarindus indica L. Fruits for the future. 1. Southampton Centre for Underutilized Crops, Southampton, U.K, 188 p.

Fretts AM, Mozaffarian D, Siscovick DS, Djousse L, Heckbert SR, King IB, McKnight B, Sitlani C, Sacks FM, Song X, Sotoodehnia N, Spiegelmann D, Wallace ER, Lemaitre RN. 2014. Plasma phospholipid saturated fatty acids and incident atrial fibrillation: The cardiovascular health study. J. Am. Heart Assoc. 3, 1-10. https://doi.org/10.1161/ JAHA.114.000889

Hondelmann W, Radatz W. 1982. Fatty-acids in seed-oils of European wild plants-a starting-point for developing industrial crops? Fett Wiss. Technol. 84, 73-75. https://doi. org/10.1002/lipi.19820840207

Horwitz W. 1995. Official methods of analysis of the Association of Official Analytical Chemists. AOAC Washington DC, US.

Kumar CS, Bhattacharya S. 2008. Tamarind seed: Properties, processing and utilization. Crit. Rev. Food Sci. 48, 1-20. https://doi.org/10.1080/10408390600948600

Lambelet P, Raemy A. 1983. Iso-solid diagrams of fat blends from thermal analysis data. J. Am. Oil Chem. Soc. 60, 845-847. https://doi.org/10.1007/BF02787442

Lemaitre RN, King IB, Rice K, McKnight B, Sotoodehnia N, Rea TD, Johnson CO, Raghunathan TE, Cobb LA, Mozaffarian D, Siscovick DS. 2014. Erythrocyte very longchain saturated fatty acids associated with lower risk of incident sudden cardiac arrest. Prostag. Leukotr. Ess. 91, 149-153. https://doi.org/10.1016/j.plefa.2014.07.010

Lemaitre RN, Fretts AM, Sitlani CM, Biggs ML, Mukamal K, King IB, Song X, Djoussé L, Siscovick DS, McKnigth B, Sotoodehnia N, Kizer JR, Mozaffarian D. 2015. Plasma phospholipid very-long-chain saturated fatty acids and incident diabetes in older adults: The cardiovascular health study. Am. J. Clin. Nutr. 101, 1047-1054. https://doi.org/ 10.3945/ajen.114.101857

Melzer M, Blin J, Bensakhria A, Valette J, Broust F. 2013. Pyrolysis of extractive rich agroindustrial residues. $J$ Anal. Appl. Pyrol. 104, 448-460. https://doi.org/10.1016/j. jaap.2013.05.027

Morad MM, El Magoli SB, Sedky KA. 1978. Physicochemical properties of Egyptian tamarind seed oil. Fett Wiss. Technol. 80, 357-359. https://doi.org/10.1002/lipi.19780800906

O'Brien RD. 2008. Fats and oils: formulating and processing for applications. CRC press. https://doi.org/10.1201/ 9781420061673

OriginLab. 2007. Origin Pro 8 SRO. OriginLab Corporation. Northampton, MA, US

Pitke PM, Singh PP, Srivastava HC. 1977. Fatty acid composition of Tamarind kernel oil. J. Am. Oil Chem. Soc. 54, 592-592. https://doi.org/10.1007/BF03027644

Quehenberger O, Armando AM, Brown AH, Milne SB, Myers DS, Merrill AH, Bandyopadhyay S, Jones KN, Kelly S, Shaner RL, Sullards CM, Wang E, Murphy RC, Barkley RM, Leiker TJ, Guan Z, Laird GM, Six DA, Russell DW, McDonald JG, Subramaniam S, Fahy E, Dennis EA. 2010. Lipidomics reveals a remarkable diversity of lipids in human plasma. J. Lipid Res. 51, 3299-3305. https://doi.org/10.1194/jlr.M009449

Rabelo SN, Ferraz VP, Oliveira LS, Franca AS. 2015. FTIR analysis for quantification of fatty acid methyl esters in biodiesel produced by microwave-assisted transesterification. Int. J. Environment. Sci. Develop.6, 964-969. https:// doi.org/10.7763/IJESD.2015.V6.730

Rao AS, Kumar AA, Ramana MV. 2015. Tamarind seed processing and by-products. Agric. Eng. Int.: CIGR J. 17, 200-204.

Rasala TM, Kale VV, Lohiya GK, Moharir KS, Ittadwar AM, Awari JG. 2011. Chemistry and pharmaceutical applications of excipients derived from tamarind. Asian J. Chem. 23, 1421-1423.

Reddy SG, Rao JMS, Achyuta Ramayya D, Azeemoddin G, Rao TSD.1979. Extraction, characteristics and fatty acid composition of tamarind kernel oil. J. Oil Technol. Assoc. India. 11, 91-93.

Roos YH, 2016. Phase transitions in foods. Academic Press. https://doi.org/10.1016/c2012-0-06577-5

Sahle FF, Gebre-Mariam T, Dobner B, Wohlrab J, Neubert RH. 2015. Skin diseases associated with the depletion of stratum corneum lipids and stratum corneum lipid substitution therapy. Skin Pharmacol. Physiol. 28, 42-55. https:// doi.org/10.1159/000360009

Shahidi F, Wanasundara PKJPD. 2002. Extraction and analysis of lipids. In: Food Lipids, Chemistry, Nutrition, and Biotechnology. Marcel Dekker, Inc. NY. US.

Santos JCO, Santos IMG, Conceiçăo MM, Porto SL, Trindade MFS, Souza AG, Prassad S, Fernandez VJ, Araújo A. 2004. Thermoanalytical, kinetic and rheological parameters of commercial edible vegetable oils. J. Therm. Anal. Calorim. 75, 419-428. https://doi.org/10.1023/b:jtan.0000027128. $62480 . \mathrm{db}$

Solís-Fuentes J, Ayala-Tirado RA, Fernández-Suárez AF, Durán-de Bazúa MC. 2015. Mamey sapote seed oil (Pouteria sapota). Potential, composition, fractionation and thermal behavior. Grasas Aceites 66 (1), e056. https://doi. org/10.3989/gya.0691141

Spitzer V, Marx F, Maia JGS, Pfeilsticker K. 1990. Curupira tefeensis (Olacaceae) - A rich source of very long-chain fatty-acids. Fett Wiss. Technol. 92, 165-168. https://doi. org/10.1002/lipi.19900920410

Sultana R, Gulzar T. 2012. Proximate analysis of Adenanthera pavonina L. seed oil, a source of lignoceric acid grown in Pakistan. J. Am. Oil Chem. Soc. 89, 1611-1618. https://doi. org/10.1007/s11746-012-2073-3

Tan CP, Che Man YB. 2000. Differential scanning calorimetric analysis of edible oils: comparison of thermal properties and chemical composition. J. Am. Oil Chem. Soc.77, 143-155. https://doi.org/10.1007/s11746-000-0024-6 